\title{
AGROINDÚSTRIAS FAMILIARES: UM ESTUDO COMPARATIVO ENTRE REGIÕES DO BRASIL E ITÁLIA
}

\author{
Family Agroindustries: A Comparative Study between Regions of Brazil and Italy
}

\section{RESUMO}

O objetivo do trabalho é investigar, comparativamente, as agroindústrias familiares no Brasil (Rio Grande do Sul) e Itália (Toscana), de maneira a perceber suas diferenças em relação a aspectos centrais dos seus processos de reprodução social e econômica. Nesse sentido, foram avaliados indicadores em torno da origem das agroindústrias, produtos elaborados, mercados e canais de comercialização construídos, políticas e programas públicos de apoio, bem como as legislações agroalimentares que regem a produção, distribuição e o consumo dos alimentos. A metodologia utilizada foi a pesquisa qualitativa, por meio da aplicação de quatorze entrevistas semiestruturadas. Também foram usados dados e informações quali-quantitativas de várias fontes secundárias. Os resultados e conclusões apontam para diferenciações interessantes entre as duas realidades regionais, entre as quais se destacam: as diferentes estratégias de qualificação agroalimentar acionadas, a forma em que são construídos socialmente os mercados e as possibilidades dos atores sociais gerarem inovações nas agroindústrias e no ambiente institucional em que se encontram imersos.

Marcio Gazolla

Universidade Tecnológica Federal do Paraná

marciogazolla1@gmail.com

Sergio Schneider

Universidade Federal do Rio Grande do Sul

schneide@ufrgs.br

Gianluca Brunori

Università Degli Studi di Pisa

gianluca.brunori@unipi.it

Submetido em: 05/07/2016. Aprovado em: 25/05/2018.

Avaliado pelo sistema double blind review

Avaliador científico: Renato Silvério Campos

DOI: 10.21714/2238-68902018v20n1p030

\begin{abstract}
The objective of this work is to investigate, comparatively, family agroindustries in Brazil (Rio Grande do Sul) and Italy (Tuscany), in order to perceive their differences in relation to the central aspects of their processes of social and economic reproduction. In this sense, indicators were evaluated on the origin of agroindustries, processed products, markets and marketing channels built, public support policies and programs, as well as agri-food legislation governing the production, distribution and consumption of food. The methodology used was qualitative research, through the application of fourteen semi-structured interviews. Qualitative and quantitative data and information from various secondary sources were also used. The results and conclusions point to interesting differences between the two regional realities, such as the: different agrifood qualification strategies, the way in which markets are socially constructed and the possibilities of social actors to generate innovations in agroindustries and the environment institutional context in which they are embededdness.
\end{abstract}

Palavras-chave: Alimentos, Mercados, Políticas Públicas, Legislações Alimentares, Desenvolvimento Rural e Regional.

Keywords: Foods, Markets, Public Policy, Legislations Foods, Regional and Rural Development.

\section{INTRODUÇÃO}

O sistema agroalimentar mundial tem se desenvolvido baseado nas cadeias longas de suprimentos, produzindo alimentos cada vez mais processados e possuindo grande dominância nos seus processos de coordenação pelos grandes atores globais, como empresas, grupos econômicos e varejistas (PLOEG, 2008). Além disso, a maioria dos alimentos comercializados são desconectados dos locais/regiões de produções e da agricultura, são produzidos e comercializados sem levar em conta aspectos ambientais, sociais e da saúde humana (LANG; HEASMAN, 2009).

Por dentro desse sistema agroalimentar hegemônico e globalizado, têm emergido várias iniciativas 'alternativas', utilizando-se oportunamente das suas 'fissuras' e fraquezas. São exemplos disso, as redes agroalimentares alternativas, 
as cadeias curtas de comercialização, os alimentos orgânicos e os produtos com alto valor agregado e com qualidades específicas e diferenciados, como os provenientes das agroindústrias familiares (RENTING, MARSDEN, BANKS, 2003; SCHNEIDER; GAZOLLA, 2015).

Nesse último caso, as agroindústrias familiares podem ser compreendidas por cinco elementos que as caracterizam e as definem como nova prática de desenvolvimento rural (GAZOLLA, 2013): (a) a forma familiar de produção, gestão e trabalho nas agroindústrias, aliada à capacidade de agência dos agricultores; (b) a pequena e média escala ligada à produção de alimentos com qualidades específicas; (c) a existência de uma base material de recursos que é estrategicamente autocontrolada pelas famílias e baseada nos fundamentos da economia de escopo; (d) agregação de valor às próprias matérias primas produzidas pela família (a característica central das agroindústrias) e; (e) a comercialização dos alimentos em mercados locais/regionais e por meio das cadeias curtas agroalimentares $^{1}$.

As pesquisas sobre esse tema, no Brasil, avançaram em vários flancos, a partir dos anos de 1990. Em um primeiro momento, os estudos trataram do entendimento das especificidades de escala e nos diferenciais dos alimentos transformados artesanalmente (PREZZOTO, 2002) e a formação de redes de cooperação e de desenvolvimento rural nas regiões em que essas iniciativas ocorriam com mais expressão (MIOR, 2005). Na virada do século, os estudos dirigemse aos temas da comercialização, analisando como essas experiências constroem socialmente seus mercados locais e regionais (WILKINSON, 2008). No momento atual, a preocupação tem-se voltado à análise das políticas públicas e do papel do ambiente institucional no desenvolvimento das agroindústrias (RAUPP, 2009; WESZ, 2009). Além disso, o tema das cadeias curtas agroalimentares tem surgido como uma nova abordagem para compreender os papéis desempenhados pelos mercados locais e regionais nos processos de desenvolvimento rural das iniciativas (GAZOLLA; SCHNEIDER, 2017).

${ }^{1}$ Quando se menciona no texto a expressão "alimentos processados" não se está referindo à categoria que consta no Guia Alimentar Brasileiro, que é uma classificação que remete aos alimentos industrializados por médias e grande empresas de alimentos, geralmente produzidos em massa e com técnicas industriais de manipulação. A categoria "alimentos processados" utilizada em relação às agroindústrias, nos dois países, refere-se aos processos artesanais e criativos de elaboração de alimentos realizados por agricultores familiares e camponeses.
Contudo, todo esse corpus de trabalhos é voltado a realidades locais, estudos de casos específicos ou em análises regionais, não constituindo um todo sedimentado de conhecimentos e análises das experiências de agregação de valor, nem mesmo de forma comparativa entre regiões brasileiras $^{2}$. Nesse sentido, não há uma literatura analítica das agroindústrias familiares em nível internacional, que permite a compreensão das dinâmicas comparadas dessas iniciativas. É com esse intuito que o presente texto visa contribuir, essencialmente respondendo à seguinte questão: como ocorrem os processos de reprodução social e econômica das agroindústrias familiares no Brasil e na Itália?

Nesse sentido, o objetivo do trabalho foi o de investigar, comparativamente, as agroindústrias familiares no Brasil (RS) e Itália (Toscana), de maneira a perceber suas diferenças e similitudes em relação a aspectos centrais dos seus processos de reprodução social e econômica. Foram avaliados indicadores em torno da origem das agroindústrias, produtos elaborados, mercados e canais de comercialização construídos, políticas e programas públicos de apoio, bem como as legislações agroalimentares que regem a produção, distribuição e o consumo dos alimentos (o que se chama de ambiente institucional).

Do ponto de vista metodológico, o trabalho pesquisou quatorze (14) agroindústrias familiares, sete no Brasil e sete na Itália, de diferentes cadeias produtivas e relacionamentos com o ambiente institucional. Junto às quatorze iniciativas, foram aplicadas, no ano de 2011, entrevistas semiestruturadas. Também foram usados dados secundários coletados de várias fontes, nos dois países. O trabalho está dividido em cinco seções, além desta introdução e das considerações finais. Na segunda parte, apresenta-se a agregação de valor como uma nova prática/estratégia de desenvolvimento rural. Na terceira, a metodologia da pesquisa, os casos estudados e as regiões pesquisadas. Das seções quatro a sete estão discutidos os principais resultados comparativos do trabalho, baseandose nas variáveis já mencionadas acima.

\section{AGREGAÇÃO DE VALOR E DESENVOLVIMENTO RURAL}

Esta seção objetiva apresentar o referencial teórico em torno da agregação de valor na agricultura familiar

\footnotetext{
2Uma exceção é a obra organizada por Schneider et al (2014) em que se compara as realidades e dinâmicas das agroindústrias e de outras experiências entre o Sul e o Nordeste brasileiro do ponto de vista da inventividade e criatividade dos atores sociais que atuam nas experiências.
} 
como uma (nova) estratégia de desenvolvimento rural, bem como definir e caracterizar o que se entende pelo objeto teórico em estudo - as agroindústrias familiares.

Segundo Ploeg (2008), a agricultura 'moderna' gerou três grandes desconexões (Figura 1). Primeiro houve uma desconexão entre a sociedade e a agricultura 'moderna', que envolveu a falta de conhecimentos da sociedade sobre as formas de fazer agricultura, sistemas produtivos, agricultores e os alimentos que chegam à mesa dos consumidores. A segunda desconexão envolve a agricultura e a natureza, na qual as práticas agrícolas cada vez mais se dirigem no sentido de abandonar a base natural de produção, na tentativa de intensificar a produção dos alimentos. A terceira desconexão em curso é das populações rurais em relação à agricultura 'moderna', já que esta expulsa cada vez mais seus habitantes, em vez de assegurar sua permanência e seus processos reprodutivos rurais.

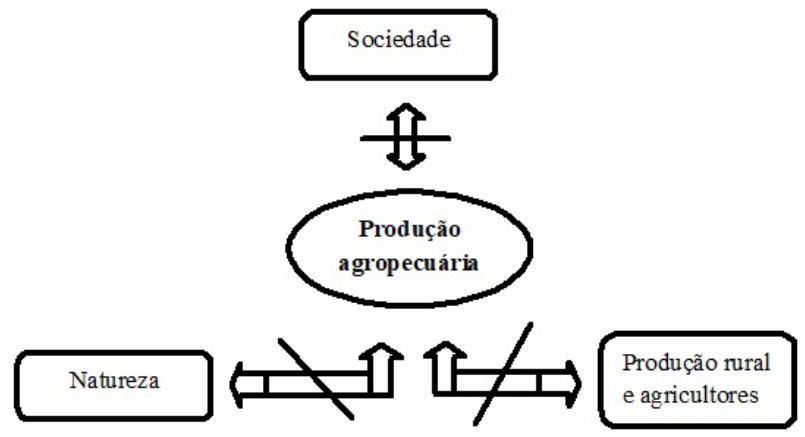

FIGURA 1 - As desconexões em curso Fonte: Ploeg (2008)

Segundo Ploeg (2002), há espaços de manobra para o rural reconstruir-se frente a essas desconexões. Para o autor, as (novas) práticas de desenvolvimento rural devem ampliar as fronteiras da agricultura 'moderna', incluindo outras atividades, cadeias produtivas, novos mercados, estratégias não agrícolas e agrícolas de reprodução social. Dentro dessa ideia, os agricultores teriam que realizar uma ampliação do espaço rural e agrícola (agroturismo, novos produtos rurais, diversificação da produção e desenvolver gestão do território/paisagem rural); uma refundação agrícola e não agrícola (envolveria a realização de uma agricultura mais econômica, pluriatividade e produção de bioenergia) e agregar maior valor à produção (agricultura orgânica, produtos de alto valor agregado, produtos territoriais/locais e vender por meio de cadeias curtas de abastecimento, agroindústrias).
É dentro dessa última estratégia de desenvolvimento rural que este trabalho analisa o potencial de agregação de valor aos alimentos e produtos da agricultura familiar, por meio de suas agroindústrias. A literatura relata alguns efeitos dessas experiências nos espaços rurais: geram produtos de maior valor agregado, comercializam pelas cadeias curtas de abastecimento, manter as famílias no campo, gerar renda e ocupações às populações rurais, dinamizar a economia local, diversificação produtiva, produzir alimentos com qualidades diferenciadas aos consumidores locais, funcionar com base em economias de escopo, formar redes alternativas em relação ao sistema agroalimentar hegemônico, entre outros benefícios que esse tipo de atividade traz aos espaços rurais e consumidores (MIOR, 2005; WILKINSON, 2008; GAZOLLA; SCHNEIDER, 2015).

Do ponto de vista do objeto de investigação, as agroindústrias familiares são definidas por uma série de elementos que as caracterizam. Mior (2005, 2007, p. 13) afirma que dois aspectos são centrais à viabilização da agregação de valor na agroindústria rural. O primeiro decorre do fato dos agricultores utilizarem seus próprios recursos, força de trabalho, processos artesanais de produção e da pequena escala para viabilizar a atividade de processamento. O segundo diz respeito ao uso do saberfazer incorporado a uma cultura regional (os alimentos passam uma imagem de aspectos artesanais, coloniais, agroecológica, local, dentre vários outros atributos que lhes proporcionam acesso aos mercados e valor econômico adicionado).

Mior (2005) ainda sustenta que os seguintes aspectos podem ser elencados como característicos dessa forma de produção e trabalho: a) localização no meio rural; b) utilização de máquinas, equipamentos e escalas menores; c) procedência própria da maior parte das matérias-primas processadas ou utilização daquela produzida por vizinhos; d) processos artesanais próprios de fabricação dos alimentos; e) utilização de mão-de-obra familiar; f) existência de associações entre famílias com grau de parentesco ou individuais e; g) internalização crescente dos aspectos regulatórios e fiscais nos empreendimentos.

Já Maluf (2004), afirma que as agroindústrias reproduzem-se porque estabelecem uma estrutura produtiva e uma lógica organizacional que lhes permite produzir a própria matéria-prima agrícola, agregando valor por meio do processamento. As unidades realizam a agregação de valor como uma entre outras atividades econômicas, sempre observando a combinação dos 
recursos (insumos, trabalho, capital, etc.) com o conjunto dos processos (re)produtivos. Assim, elas buscam manter a diversificação como principio básico de sua organização que visa a reduzir o grau de vulnerabilidade face às contingências da produção agrícola e dos próprios mercados agroalimentares.

Para Maluf(2004), as agroindústrias reproduziramse com base em três atributos fundamentais: a) a economia em pequena escala de processamento dos alimentos; b) um modelo de agroindustrialização descentralizado e; (c) as unidades agroindustriais desenvolve-se com uma perspectiva que leva em conta outros aspectos, além daqueles estritamente normativos e regulamentares formais para definir os padrões qualitativos dos alimentos. A esses elementos, poder-se-ia adicionar o que Wilkinson (2008) propõe em termos de mercados: a ideia de que os produtos e alimentos das agroindústrias circulam principalmente pelos mercados de proximidade social, em função de serem construídos embededdness nas relações sociais locais de produção-consumo (compras frequentes, interconhecimento, redes sociais, relações de amizade, relações e contatos informais, valores sociais compartilhados).

Em termos numéricos, a importância das agroindústrias familiares tem sido ressaltada nos últimos anos nos dois países. No Brasil, estimativas do extinto Ministério do Desenvolvimento Agrário (MDA) apontam para a existência de aproximadamente 35 mil agroindústrias (em 2008). Já os dados do Censo Agropecuário (IBGE, 2006) destacam que $16,7 \%$ dos estabelecimentos rurais beneficiam alguma matéria-prima. No caso italiano, não há estatísticas específicas desse setor, já que os estudos rurais no país são voltados a entender de forma ampla as dinâmicas e processos de reprodução social das aziendas agricolas.

Contudo, um estudo que apresenta dados aproximados é o de Renting, Marsden e Banks (2003), que analisa os alimentos e produtos que circulam em cadeias curtas na Itália, basicamente os alimentos orgânicos e o que os autores chamaram de 'especialidades' (seriam os produtos com indicação geográfica, de origem e transformados). O número de propriedades que produzem esses dois tipos de alimentos é de 186.698. Quando esse dado é relacionado com o total de propriedades existentes na Itália (em torno de 1.677.765, pelos dados de 2010), tem-se que, em torno de $11,12 \%$ destas produzem alimentos transformados, como são chamados no país esse tipo de produto. Considerando-se os dados percentuais disponíveis nos dois países, ainda que de forma aproximada, notam-se estatísticas muito próximas em relação às unidades que fazem o processamento de alimentos (uma diferença de 5,58\%), embora em termos absolutos, o número de propriedades no Brasil é mais de quatro vezes maior em relação ao italiano (em torno de 885.100 propriedades).

\section{METODOLOGIA, REGIÕES E EXPERIÊNCIAS INVESTIGADAS}

Esta seção apresenta uma caracterização das regiões investigadas nos dois países, os instrumentos metodológicos utilizados na pesquisa e uma breve descrição das agroindústrias que foram estudadas.

Na Itália, a Região de investigação foi a Toscana. É uma região da Itália Central com cerca de 3,7 milhões de habitantes e 22. $997 \mathrm{~km}^{2}$, cuja capital é Florença (Figura 2). A agricultura, silvicultura e pesca é responsável por $1,7 \%$ do Produto Interno Bruto (PIB) da economia regional e por $1,84 \%$ do PIB nacional. Essa região é conhecida mundialmente pela excelente gastronomia associada ao turismo internacional. A gastronomia é baseada em pequenos estabelecimentos (restaurantes, trattorias, negócios especializados) que possuem como base os alimentos e produtos advindos da agricultura familiar.

Segundo o Censo da Agricultura Italiana (ISTAT, 2010), o número de estabelecimentos da Região é de 72.686. Desse total, 44\% são classificados como pequenos, $36 \%$ como médios e $20 \%$ como grandes. Os dados demonstram ser a agricultura familiar a principal forma social de produção e trabalho existente nos espaços rurais Toscanos.

Segundo Relatório do INEA (2013), os principais produtos cultivados são cereais, forragens, girassol, videiras, oliveiras e flores. Do lado animal, destacam-se os bovinos, equinos, ovinos, caprinos, galinhas e perus. Dentre os 'produtos transformados" ${ }^{3}$ como são chamados os alimentos provenientes das agroindústrias têm-se vinhos e óleos. Mas também há outros, como pães, conservas de verduras, vários tipos de doces de frutas, o mel, pastas, uma grande variedade de queijos de diversas espécies animais (com destaque aos de ovelhas), os 'ensacados', entre outros produtos.

${ }^{3}$ Diferentemente do Brasil, na Itália não existe uma série de estudos rurais dedicados especificamente ao tema da agroindustrialização das matérias primas e agregação de valor rural. No caso italiano, estes produtos e alimentos são chamados de 'transformados' (tranformati) e são pesquisados pelos estudiosos das ciências sociais dentro da dinâmica maior das propriedades rurais. 
No Brasil, o estado pesquisado foi o Rio Grande do Sul, especialmente o Norte Gaúcho (Figura 2). É um local de colonização recente por imigrantes europeus, principalmente italianos, alemães, poloneses, entre outras etnias. Essa característica fez com que o Norte gaúcho desenvolvesse historicamente sistemas produtivos com a predominância da lógica familiar como forma social de produção e trabalho rural ${ }^{4}$.

Os dados do Censo Agropecuário (IBGE, 2006) ajudam a revelar a importância da agricultura de base familiar no local. A Microrregião de Frederico Westphalen, na qual foi realizada a pesquisa, possui 23.090 estabelecimentos, os que são familiares atingem $93,04 \%$ do total existente. Com relação à área, estes possuem 288.114 ha, que é igual a $73,97 \%$ da área de terras da Microrregião. Quando se analisa o pessoal ocupado na agropecuária, encontram-se 64.801 pessoas, das quais $91,86 \%$ são familiares. A média de tamanho das propriedades rurais não chega a 13,0 hectares $(12,47$ ha). Da população total, ainda, 52,83\% vivem e trabalham no rural.

Atualmente, os principais produtos cultivados na região são os grãos e commodities, como soja, milho e, no passado, o trigo. Também há grande relevância das atividades ligadas a grandes empresas integradoras

${ }^{4} E$ claro que antes da colonização por imigrantes europeus havia outros povos e populações vivendo neste local, como os indígenas, pessoas fugidas da Revolução Farroupilha, 'Guerra da Degola' e transportadores de mercadorias que usavam o local como passagem. Mas é com os imigrantes que a agricultura é iniciada mais largamente.

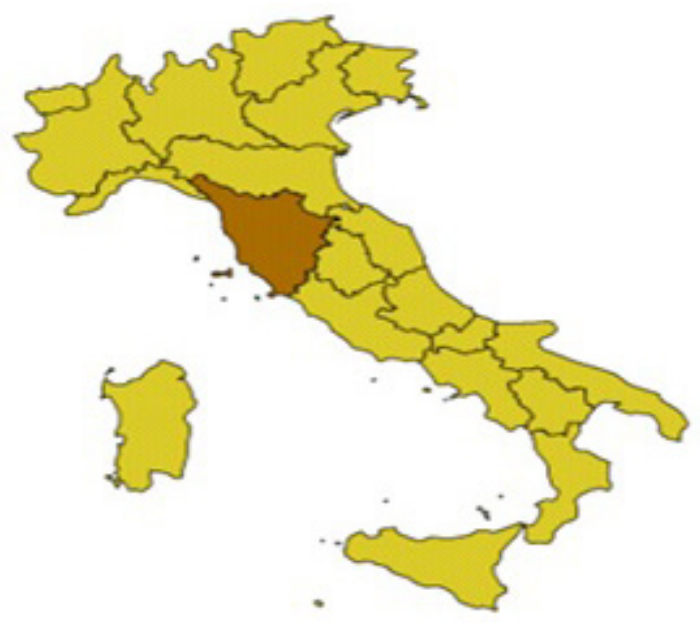

de suínos, fumicultura e aves (CONTERATO; GAZOLLA; SCHNEIDER, 2007). Além destas, a fruticultura tem crescido muito nos últimos anos. Como alternativas às atividades produtivistas, existe a agroecologia, agroindústrias e ultimamente a diversificação produtiva. No caso das agroindústrias, pesquisa realizada em 2006 revelou que há 106 empreendimentos, em 34 municípios pesquisados, de várias cadeias produtivas, com destaque para ligadas à cana de açúcar, frutas, hortaliças, panificados e vinhos (PELEGRINI; GAZOLLA, 2006).

No Quadro 1, é possível observar as iniciativas pesquisadas e ano de origem para as duas regiões investigadas. Foram estudadas sete (7) experiências, tanto no Brasil como na Itália ${ }^{5}$. Tanto no Brasil como na Itália pode-se notar que há experiências bem variadas em termos de ano de origem, algumas remontam aos anos de 1970, já outras, são mais recentes, do início deste século. Nos dois casos, as experiências pesquisadas são de diversas cadeias produtivas e possuem dinâmicas de construção de mercados e acesso a políticas públicas diferenciadas, como se mostrará nas próximas seções do trabalho.

${ }^{5} \mathrm{~A}$ amostra da pesquisa foi definida de forma intencional e dirigida, no sentido de que fossem incluídas agroindústrias familiares de diferentes cadeias produtivas, situações em relação ao ambiente institucional (legislações alimentares), acessos a diferentes mercados e canais comerciais, além de participarem de várias políticas públicas e ações institucionais. A ideia que permeou a amostragem foi de abarcar o maior número possível de iniciativas diversificadas, heterogêneas, mas acima de tudo, possuir uma amostra representativa da realidade dos dois países.

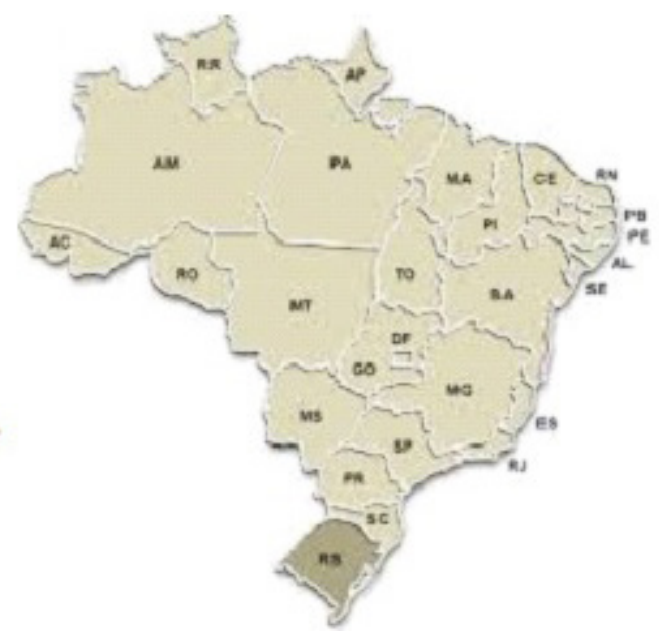

FIGURA 2 - Mapa da Itália com destaque a Região da Toscana e do Brasil com destaque para o Rio Grande do Sul Fonte: http://www.regione.toscana.it/ (2016) e www.patrimoniodetodos.gov.br (2016)

Organizações Rurais \& Agroindustriais, Lavras, v. 20, n. 1, p. 30-48, 2018 
QUADRO 1 - Regiões, ano de inicio das atividades e agroindústrias pesquisadas no Brasil (RS) e Itália (Toscana)

\begin{tabular}{|c|c|c|c|}
\hline Origem (ano) & Brasil (RS) & Origem (ano) & Itália (Toscana) \\
\hline 1986 & Agroindústria Prevedello & 1990 & Azienda Lischeto \\
\hline 2001 & Cooperativa Biorga & 1987 & Azienda Floriddia \\
\hline 1994 & Strack Alimentos Naturais & 2009 & Cooperativa Orto \& Co Frutta \\
\hline 1973 & Agroindústria Gehen & 2000 & Caseificio Pedrazzi Giampaolo \\
\hline 2002 & Agroindústria Ludke & 1990 & Azienda Fonte di Foiano \\
\hline 2009 & Agroindústria Jotti & 2005 & Azienda La Stalletta \\
\hline 2002 & Agroindústria Zonta & 1965 & Azienda Dr. Pescia \\
\hline
\end{tabular}

Fonte: Pesquisa de campo (2011); Sites das propriedades rurais: http://www.fontedifoiano.it/ (2015) e http://www.dottorpescia. $\mathrm{com} /(2016)$

Nos dois casos, a pesquisa baseou-se em dados estatísticos e pesquisa documental como forma de levantamento de informações e dados secundários ${ }^{6}$. Como dados primários e qualitativos, foram aplicadas sete (7) entrevistas semiestruturadas em cada país, com os donos das agroindústrias e suas famílias. Além disso, entrevistaram-se alguns atores sociais-chave, tanto no Brasil como na Itália, para compreender as políticas e programas públicos de apoio às experiências e as legislações agroalimentares que regulam às iniciativas?

\section{AS MOTIVAÇÕES DAS FAMÍLIAS PARA AGREGAR VALOR À PRODUÇÃO IN NATURA}

Nesta seção, serão discutidas as principais motivações das famílias em iniciar a agroindustrialização em suas propriedades. O Quadro 2 sumariza os motivos pelos quais as sete agroindústrias brasileiras originaram-se. De maneira geral, unifica-se o surgimento das agroindústrias devido a quatro vetores principais. Primeiro, os processos de aumento dos custos de produção na agricultura devido à aquisição externa de insumos e tecnologias. Também a queda das rendas agrícolas, em função dos baixos preços

${ }^{6}$ Os dados estatísticos secundários brasileiros são oriundos do IBGE, de outras pesquisas já realizadas sobre agroindústrias no Brasil e na região investigada, além de referências bibliográficas sobre o tema das agroindústrias. No caso italiano, os dados foram obtidos do INEA, da Regione Toscana, sites institucionais do governo italiano e regional da Toscana, sites das propriedades rurais e das referências sobre o tema na Itália.

${ }^{7}$ Tanto no Brasil como na Itália foram aplicadas entrevistas com agricultores, agentes de desenvolvimento rural, instituições reguladoras de alimentos, agentes do Estado, operacionalizadores de políticas públicas em diferentes níveis administrativos e territoriais. Estas entrevistas foram gravadas e degravadas (transcritas literalmente), sendo sobre as falas contidas nas mesmas, usado à técnica de análise de conteúdo para avaliar a dinâmica dos indicadores e variáveis contidos nas mesmas. Embora não se utilizou citações diretas de trechos das entrevistas no texto, a partir delas foram construídos vários quadros e tabelas contidos no mesmo. recebidos pelos produtos agropecuários (grãos). Esses dois movimentos associados, estreitaram as condições de reprodução social dos agricultores. Na literatura internacional, esse processo social tem sido descrito pelo conceito de squeeze (PLOEG, 2008) . $^{8}$.

Segundo, os agricultores buscaram alternativas a esse primeiro problema, já que não conseguiram ficar inseridos nas cadeias longas. Para efetuar isso, as famílias utilizam proativamente de diversas estratégias para montar suas agroindústrias, por exemplo, usam seus conhecimentos, recursos existentes na propriedade, buscam recursos públicos, produzem suas próprias matérias primas, trocam experiências com vizinhos, recontextualizam novos conhecimentos de fora da unidade, entre outras ações. Um aspecto que chama a atenção é que quando as famílias agem estrategicamente constituindo agroindústrias, o fazem na direção de atingir maiores graus de autonomia. Esse aspecto é expresso no Quadro 2, quando alguns agricultores apontam, por exemplo, a "vontade de possuírem seu próprio negócio", para não serem dependentes ou empregados, confluindo com o que apontam os estudos de Long (2001) sobre a capacidade de agência dos atores sociais.

Terceiro, os conhecimentos históricos dos agricultores dos processos de elaboração de alimentos são colocados em prática, pois as famílias já possuíam a tradição de processar (Quadro 2). A esses conhecimentos somam-se outros tipos que proveem de fora das unidades, como dos agentes de desenvolvimento, serviços de

\footnotetext{
${ }^{8} \mathrm{~A}$ tradução para a palavra squeeze significa "aperto", "compressão" ou "estreitamento". É a situação gerada pelo processo de modernização da agricultura, em que os agricultores são comprimidos entre, de um lado, o aumento dos custos de produção de insumos e tecnologias externas a propriedade e, de outro, pela diminuição nos preços dos principais produtos agrícolas e alimentos, gerando um processo de queda constante na rentabilidade das atividades produtivas.
} 
extensão rural, cursos, viagens, trocas de experiências. Esses conhecimentos agem sobre uma base de recursos dos agricultores pré-existente nas unidades, que são a produção diversificada das propriedades (por exemplo, $\mathrm{o}$ autoconsumo) e seus recursos básicos (água, terra $\mathrm{e}$ objetos de trabalho). Este resultado da pesquisa conflui com os estudos de Stuiver (2008) e Stuiver e Wiskerke (2004) ao apontar que, os conhecimentos tácitos e contextuais dos agricultores geram novas práticas sociais e produtivas na agricultura como são as agroindústrias familiares.

Quarto, o surgimento das agroindústrias também dependeu das ações governamentais, serviços de apoio como extensão rural e do papel de algumas instituições (Quadro 2). Basicamente, as instituições e ações governamentais apoiam essas agroindústrias com novos conhecimentos, fornecimento de infraestrutura para processamento dos alimentos (prédios e máquinas agroindustriais), assistência técnica e extensão rural, no processo de formalização as regras alimentares e crédito rural. A conjugação desses quatro elementos mencionados de forma integrada e multifacetada na realidade institucional é que faz surgir essa nova estratégia de desenvolvimento rural brasileira.

No caso das experiências italianas há também uma conjunção de fatores que explicam o seu surgimento, conforme o Quadro 3. Esses aspectos são 'classificados' em quatro processos sociais. O primeiro são os conhecimentos históricos dos agricultores, seus familiares e parentes sobre a fabricação de alimentos dentro das unidades proidutivas, que são mobilizados na hora de iniciar a atividade em torno da agroindústria. É claro que, a esses conhecimentos camponeses, hibridizam-se ao longo do tempo de vida da iniciativa com outros conhecimentos vindos de agências de desenvolvimento, assistência técnica, outros agricultores e atores sociais como os consumidores como mostra Stuiver (2008).

O segundo fator emulador das experiências é o sentimento de necessidade em torno de agregação de valor aos produtos e alimentos in natura que eram comercializados a preços baixos. A transformação dos alimentos nas agroindústrias traz a possibilidade de receber mais pelos produtos nos mercados, gerando maior renda às famílias envolvidas. No caso das experiências italianas, a agregação de valor pode ser atingida por vários processos que, muitas vezes, ocorrem de forma integrada, por exemplo, devido à valorização local e geográfica do alimento (devido a Indicação Geográfica - IG, Denominação de Origem - DP), sociocultural (de acordo com as regras gastronômicas), diferenciais ambientais dos alimentos (orgânicos), entre outros mecanismos de adição de valor aos produtos usados pelos agricultores, que tem sido chamada de 'outra modernização' (PLOEG, 2006).

O terceiro elemento que potencializa as iniciativas italianas são os novos mercados alimentares e o consumo crítico. Durante a pesquisa de campo, ficou claro que alguns agricultores iniciaram com suas atividades devido à demanda por alimentos com qualidades específicas, por exemplo, os orgânicos, o que demonstra que os agricultores europeus estão intimamente ligados às tendências dos mercados alimentares. Também nesse sentido, é importante a grande gama de produtos que circulam pelas cadeias curtas agroalimentares. No caso Toscano, estudos apontam para quase $17 \%$ das propriedades que vendem dessa forma sua produção (16,8\%) (GOSOMO, 2012). Além disso, cresce internacionalmente os consumidores chamados de reflexivos (GIDDENS; ULRICH; SCOTT, 1997), por exprimirem por meio do consumo sua ação política na sociedade, demandando alimentos com diferenciais sociais, ambientais, bem-estar animal, livre de OGM's, entre outros aspectos.

Como quarto conjunto de fatores que explicam o nascimento das experiências italianas de transformação alimentar está à atenção aos aspectos da qualidade agroalimentar que vão além dos higiênico-sanitários. A maioria dos produtos possuem qualidades que os diferenciam dos alimentos produzidos industrialmente, além de possuírem algum tipo de inovação embutida em sua fabricação. Os orgânicos são bons exemplos de alimentos com apelos ambientais, porém, têm-se também produtos diversificados (vários tipos de queijos feitos a partir do leite cru de ovelhas); mel multivarietal (produzidos por abelhas que o coletam de diversas plantas); pães, biscoitos e massas de variedades antigas de trigo duro (provenientes ainda do período Etrusco), óleos de oliva extra virgem (somente com prensa fria e sem refino químico), evidenciando ser a diferenciação e a inovação dos atores, traços constitutivos das iniciativas desde sua origem (BRUNORI et al, 2008).

\section{CADEIAS PRODUTIVAS E ALIMENTOS PROCESSADOS}

Esta seção objetiva apresentar, comparativamente, as principais cadeias produtivas e tipos de alimentos produzidos pelas iniciativas investigadas no Brasil e na Itália. O Quadro 4 apresenta essas informações para os sete casos brasileiros. Em primeiro lugar, nota-se que, embora haja certo grau de diversidade agroalimentar das experiências brasileiras 
(são 44 12,3 alimentos e produtos produzidos entre as sete agroindústrias) há iniciativas que possuem um a três produtos fabricados, evidenciando trabalharem com uma gama pequena de alimentos (em média 6,2 produtos/agroindústria). Em segundo lugar, o Quadro 4 evidencia que poucas experiências possuem diferenciais ambientais (alimentos ecológicos ou orgânicos) em seu portfólio produtivo (apenas a erva mate ecológica de barbaquá), demonstrando ser a agroindústria orgânica uma realidade pouco presente ainda no Brasil (GAZOLLA, 2012).

QUADRO 2 - Brasil (RS): Principais motivos que levaram as famílias a constituírem agroindústrias

\begin{tabular}{|c|c|}
\hline Agroindústrias & Motivos de sua criação/surgimento \\
\hline Agroindústria Prevedello & $\begin{array}{l}\text { - Exemplo de um vizinho que fazia a cachaça. A família Prevedello adquiriu dele os primeiros } \\
\text { equipamentos para a sua agroindústria; } \\
\text { - Geração de maiores rendas do que as outras atividades na dinâmica da propriedade rural; } \\
\text { - Ocupação do "tempo livre" das outras atividades no período invernal; }\end{array}$ \\
\hline Cooperativa Biorga & $\begin{array}{l}\text { - Curso de Agroecologia através da Igreja Luterana para aprender os conhecimentos iniciais sobre a } \\
\text { produção orgânica de grãos alternativos. O curso foi desenvolvido através da ONG Terra Nova de } \\
\text { Mondai/SC; } \\
\text { - Visita a uma indústria de óleos convencionais em Panambi, da qual se adquiriu alguns conhecimentos } \\
\text { sobre o processamento de óleos vegetais; } \\
\text { - Assessoria técnica em Agroecologia através do Centro de Apoio aos Pequenos Agricultores (CAPA } \\
\text { - Mondai/SC); }\end{array}$ \\
\hline $\begin{array}{c}\text { Strack Alimentos } \\
\text { Naturais }\end{array}$ & $\begin{array}{l}\text { - A família quando era agricultora sempre transformou pequenas quantidades de cana para comercializar } \\
\text { na forma de derivados, principalmente o açúcar mascavo, sendo a atividade uma tradição familiar; } \\
\text { - Habilidade e conhecimentos de comércio possuídos pelo Senhor Strack e a participação em um } \\
\text { Seminário sobre produtos naturais promovidos pela Associação Comercial e Industrial (ACI - Frederico } \\
\text { Westphalen/RS); } \\
\text { - A família compra uma indústria de cana de um grupo urbano privado de } 27 \text { sócios do Município de } \\
\text { Caiçara, constituindo a atual Agroindústria Strack Alimentos Naturais; }\end{array}$ \\
\hline Agroindústria Gehen & $\begin{array}{l}\text { - A produção de erva mate artesanal (primeiro de carijó e depois de barbaquá) é feita pela } 4^{\mathrm{a}} \text { geração } \\
\text { na família, sendo uma atividade histórica; } \\
\text { - Os conhecimentos e habilidades históricos de produção e processamento de erva mate que foram } \\
\text { repassados intergeracionalmente dentro da família; }\end{array}$ \\
\hline Agroindústria Ludke & $\begin{array}{l}\text { - História e conhecimentos familiares de produção dos derivados do leite, especialmente dos queijos } \\
\text { para autoconsumo sempre esteve presente na família; } \\
\text { - Visitas a outras iniciativas de agroindustrialização no RS e SC para adquirir conhecimentos de como } \\
\text { se organizavam e confeccionavam os alimentos; } \\
\text { - Incentivo por parte do poder público municipal e de outras instituições locais (Emater, STR, Secretaria } \\
\text { da Agricultura) para a implantação de agroindústrias no município e construção de um programa de } \\
\text { agroindustrialização familiar; }\end{array}$ \\
\hline Agroindústria Jotti & $\begin{array}{l}\text { - Possibilidade de com a agroindústria o irmão retornar de São José dos Campos/SP e ficar com a } \\
\text { família no município; } \\
\text { - Com a iniciativa a família possuiria o seu próprio negócio e renda; } \\
\text { - Apoio da Prefeitura Municipal e demais instituições locais (Emater, Secretaria da Agricultura) para } \\
\text { que se usasse um prédio já construído e alguns equipamentos que este possuía no seu interior; }\end{array}$ \\
\hline $\begin{array}{l}\text { Agroindústria Zonta } \\
\text { (antiga Natufred) }\end{array}$ & $\begin{array}{l}\text { - Cursou Ciências Contábeis, sendo que o curso o incentivou a colocar um negócio próprio na agricultura } \\
\text { e os próprios sócios da experiência já pensavam dessa forma; } \\
\text { - Influências de um Agrônomo da Emater de Frederico Westphalen que os convenceu que deveriam } \\
\text { investir na produção de uvas, seja para vendas in natura e/ou processada; } \\
\text { - Os sócios fizeram um curso de processamento de uvas na Fazenda Souza, da Fepagro, em Caxias do } \\
\text { Sul, no qual apreenderam os conhecimentos para a nova atividade. Este foi decisivo em fortalecer as } \\
\text { suas convicções em torno da confecção dos novos produtos na unidade; }\end{array}$ \\
\hline
\end{tabular}

Fonte: Pesquisa de campo (2011) 
QUADRO 3 - Itália (Toscana): Principais motivos que levaram as famílias a constituírem agroindústrias

\begin{tabular}{|c|c|}
\hline Agroindústrias & Motivos de sua criação/surgimento \\
\hline Azienda Lischeto & $\begin{array}{l}\text { - Experiência histórica e conhecimentos em torno do pastoreio de ovelhas, produção de leite e } \\
\text { processamento de queijos; } \\
\text { - Busca de antigas receitas familiares e de vizinhos, bem como de novas receitas de produtos processados; } \\
\text { - Os mercados requeriam cada vez mais alimentos com qualidades biológicas e ligados aos atributos } \\
\text { territoriais (clima, solo, saberes, etc.); }\end{array}$ \\
\hline Azienda Floriddia & $\begin{array}{l}\text { - Disponibilidade de variedades antigas de farro e de trigos duros (algumas desde o período Etrusco); } \\
\text { - Opção familiar pela conversão da agricultura convencional a biológica (menores custos de produção } \\
\text { das lavouras de cereais); } \\
\text { - Crescimento dos mercados de alimentos biológicos e a procura dos consumidores "atentos" } \\
\text { (consumidores conscientes das vantagens dos orgânicos); } \\
\text { - Programa de Desenvolvimento Rural (PDR) financiou a aquisição de um pequeno moinho de cereais; }\end{array}$ \\
\hline $\begin{array}{c}\text { Cooperativa Orto \& Co } \\
\text { Frutta }\end{array}$ & $\begin{array}{l}\text { - Ação coletiva de cinco agricultores que formam a cooperativa para buscar maior valorização pelos } \\
\text { seus alimentos comercializados; } \\
\text { - Possuir maiores forças frente a grande distribuição alimentar (duas grandes redes de supermercados } \\
\text { italianos Coop e Conad); } \\
\text { - Formar um portfólio de propriedades rurais que comercializam seus produtos de forma conjunta (20 } \\
\text { propriedades rurais); }\end{array}$ \\
\hline $\begin{array}{l}\text { Caseificio Pedrazzi } \\
\text { Giampaolo }\end{array}$ & $\begin{array}{l}\text { - Fim do pastejo transumante das ovelhas, fixando-se ao interior do Parque San Rossore; } \\
\text { - Os preços do leite caiam e do queijo se elevava, incentivando a transformação da matéria prima; } \\
\text { - Fabricar alimentos de "nicho" com valor agregado alto para os mercados locais; }\end{array}$ \\
\hline Azienda Fonte di Foiano & $\begin{array}{l}\text { - Aquisição da propriedade rural na Toscana, onde iniciaram o cultivo de oliveiras (antes trabalhavam } \\
\text { com cosméticos na cidade); } \\
\text { - Vendiam a oliveira in natura, mas sentiram a necessidade de agregar valor ao próprio produto, } \\
\text { fabricando óleos de oliva na propriedade; }\end{array}$ \\
\hline Azienda La Stalletta & $\begin{array}{l}\text { - Baixos preços recebidos pelo leite vendido in natura; } \\
\text { - Necessidade de agregar valor à produção de leite, na forma de fabricação de queijos; } \\
\text { - Conhecimentos históricos existentes na família de trabalho com o gado leiteiro e a fabricação de queijos; }\end{array}$ \\
\hline Azienda Dr. Pescia & $\begin{array}{l}\text { - Conhecimentos familiares históricos em torno da produção e processamento de mel; } \\
\text { - Produção de mel multivarietal através da técnica do nomadismo das colméias; } \\
\text { - Busca de possuir seu próprio negócio e atividade de manutenção familiar (antes trabalhava em dois } \\
\text { trabalhos fora da agricultura); }\end{array}$ \\
\hline
\end{tabular}

Fonte: Pesquisa de campo (2011) e Sites das propriedades rurais: http://www.agrilischeto.com/ (2015); http://www.ilmulinoapietra. it/ (2015); http://www.fontedifoiano.it/ (2015); http://www.dottorpescia.com/ (2016)

Já do ponto de vista das cadeias produtivas, as experiências brasileiras desenvolvem-se a partir da cana de açúcar e derivados (cachaça, melado, açúcar mascavo, rapadura e álcool), dos chamados 'grãos alternativos' (linhaça, gergelim, amendoim e seus respectivos óleos), erva mate ecológica de barbaquá (infusão típica do Sul do país), leite bovino e derivados (queijo colonial, temperado, parmesão), carne suína e derivados (salames, salsichão, linguiças, bacon, morcilhas, carnes in natura, banha, ossos, etc.) e os derivados da uva (sucos, vinhos e graspa).

No caso das experiências italianas, os alimentos elaborados pelas famílias são distintos dos casos brasileiros, conforme o Quadro 5. Primeiro, nota-se uma grande diversidade agroalimentar das sete agroindústrias investigadas na Itália. Elas elaboram em torno de 104 produtos e alimentos, possuindo uma média de 14,8 produtos/agroindústria, mais do que o dobro em relação às iniciativas brasileiras. A experiência que menos produz possui cinco tipos de azeites de oliveira, quase a média dos casos estudados no Brasil.

Muito eloquente, também, é a grande diversidade de atributos qualitativos (inovações produtivas) em que se apresentam os alimentos das iniciativas italianas. Notase que três das sete agroindústrias elaboram produtos biológicos (usa-se esta nomenclatura para os produtos orgânicos), que possuem diferenciais de qualidade ambiental. Uma experiência fabrica derivados de frutas com matérias primas da agricultura integrada (utiliza 
QUADRO 4 - Brasil (RS): As sete agroindústrias investigadas e principais alimentos/produtos elaborados

\begin{tabular}{|c|l|}
\hline Agroindústrias & \multicolumn{1}{|c|}{ Produtos produzidos e processados } \\
\hline Agroindústria Prevedello & Cachaça, cachaça envelhecida em barril de carvalho e álcool para consumo próprio (carro e moto) \\
\hline Cooperativa Biorga & $\begin{array}{l}\text { Linhaça, trigo, feijão, milho pipoca, amendoim, gergelim, óleos de gergelim e linhaça, canjica de milho, } \\
\text { farinhas de milho, de gergelim, de linhaça e trigo }\end{array}$ \\
\hline $\begin{array}{c}\text { Strack Alimentos } \\
\text { Naturais }\end{array}$ & Melado batido, melado fino (“cotovelo"), açúcar mascavo e rapadura colonial \\
\hline Agroindústria Gehen & Erva mate ecológica de barbaquá \\
\hline Agroindústria Ludke & Queijo colonial, parmesão e temperados \\
\hline Agroindústria Jotti & $\begin{array}{l}\text { Salame colonial, cracóvia e calabresa, salsichão, linguiça mista defumada, bacon e costela defumados, } \\
\text { morcilhas, mortadela (em teste), torresmo prensado e pururuca ("casquinha"), codeguins, carne in } \\
\text { natura, banha, ossinhos }\end{array}$ \\
\hline Agroindústria Zonta & Suco de uva, vinhos bordô, isabel e branco e graspa \\
\hline Total & 44 alimentos e produtos \\
\hline
\end{tabular}

Fonte: Pesquisa de campo (2011)

QUADRO 5 - Itália (Toscana): As sete agroindústrias investigadas e principais produtos/alimentos elaborados

\begin{tabular}{|c|c|}
\hline Agroindústrias & Produtos produzidos e processados \\
\hline Azienda Lischeto & $\begin{array}{l}\text { Queijos de ovelha biológicos (cacio del monsignore, caciotta degli sposi, pecorino degli sposi, } \\
\text { raveggiolo dei priori, pecorino maschio, pecorino rosso volterrano, tomini innovativi, balze (DOP)); } \\
\text { ricota biancana; tricota divina; iogurte; mel; massa biológica artesanal; óleo biológico extra virgem de } \\
\text { oliva; cosméticos a base de leite de ovelhas e de óleo de oliva extra virgem. }\end{array}$ \\
\hline Azienda Floriddia & $\begin{array}{l}\text { Massa biológica de farro monocozida } 100 \% \text {; massa glúten e doença celíaca; massa biológica com } \\
\text { germem de trigo; massa biológica de farro duocozida } 100 \% \text {; massa biológica de trigo Etrusco } 100 \% \text {; } \\
\text { massa biológica; massa biológica artesanal para restauração; massa biológica Senador Cappelli; massa } \\
\text { mãe biológica; pão biológico; biscoitos biológicos, farinhas de trigo e farro biológicas. }\end{array}$ \\
\hline $\begin{array}{l}\text { Cooperativa Orto \& Co } \\
\text { Frutta }\end{array}$ & $\begin{array}{l}\text { Frutas (pêssegos, ameixas, melancia, melões, cerejas, amora) e verduras (abobrinhas, abóbora, batata } \\
\text { branca, tomates) in natura; doces em massa (cerejas, pêssego, amora, ameixas e morango) (todos } \\
\text { alimentos da agricultura integrada); }\end{array}$ \\
\hline $\begin{array}{l}\text { Caseificio Pedrazzi } \\
\text { Giampaolo }\end{array}$ & $\begin{array}{l}\text { Queijos de ovelha biológicos frescos (raviggiolo e baccellone); queijos biológicos envelhecidos por } \\
\text { diferentes períodos de tempo (curto, médio e longo períodos); queijos biológicos (com nozes, com } \\
\text { pinhões, com pimentas, com pimentões, com ervas aromáticas (ex.: orégano), com pistacchio); queijo } \\
\text { de ovelha grinzoso; iogurte natural biológico; iogurte com pistacchio; ricota biológica; tomini biológico; }\end{array}$ \\
\hline Azienda Fonte di Foiano & Óleos de oliva extra virgem (IGP Toscano, monovarietal moraiolo, monovarietal frantoio, cru, grand cru); \\
\hline Azienda La Stalletta & $\begin{array}{l}\text { Leite, ricota, iogurte, queijo mussarela flor de leite, queijo caciotte speciate, queijo vermelho canhestro, } \\
\text { queijo cacio embaixo da palha, queijo strancchinella, queijo canhestro del marmolaio, queijo cacio } \\
\text { apimentado e queijo caciotta; }\end{array}$ \\
\hline Azienda Dr. Pescia & $\begin{array}{l}\text { Mel mono florais (Castanha, Acácia, Sulla, Erva médica, Girassol, Macchia mediterrânea, Rovo, } \\
\text { Corbezzolo, Edera e de bosque), mel multiflorais (Mil flores), Polline e geleia real, própolis, produtos } \\
\text { de higiene e cosméticos fabricados a partir do mel (creme hidratante para rosto, creme anti idade para } \\
\text { rosto, Creme de contorno para olhos, creme para as mãos, creme para corpo, banho e ducha, sabonete } \\
\text { líquido, shampoo e balsamo), cera e hidromel; }\end{array}$ \\
\hline Total & 104 produtos e alimentos \\
\hline
\end{tabular}

Fonte: Pesquisa de campo (2011) e Site das propriedades rurais: http://www.agrilischeto.com/ (2015); http://www.ilmulinoapietra.it/ (2015); http://www.aziendaagricolapedrazzi.it/ (2015); http://www.fontedifoiano.it/ (2015); http://www.lastalletta.it/ (2016); http:// www.dottorpescia.com/ (2016) 
menores níveis de fertilização e insumos, além do manejo de ervas e insetos com técnicas provenientes do controle biológico). Outra iniciativa possui manejo natural das oliveiras e produz óleos virgens com apenas a prensa a frio e sem refino químico. Os alimentos e produtos dos casos italianos preocupam-se mais em diferenciar os aspectos qualitativos que os formam, e são mais inovadores em relação aos brasileiros (ARFINI; BELLETTI; MARESCOTTI, 2010).

A grande diversidade de alimentos feitos com a mesma matéria prima é também uma marca das agroindústrias italianas, nas diversas cadeias produtivas. Têm-se vários tipos de queijos biológicos elaborados a partir do leite crú de ovelha biológico (chamados de pecorinos, pecorinos envelhecidos, pecorinos com Denominação de Origem Protegida - DOP, ricota, iogurte, tomini e cosméticos a base de leite de ovelhas), alimentos à base de farro biológico (variedade de trigo duro cultivado desde o período Etrusco), que produz vários derivados (pães, massas, biscoitos, farinhas), derivados de frutas e verduras (ameixas, pêssegos, amoras, abóbora, batatas, tomates), derivados da oliveira (diversos azeites, alguns com Indicação Geográfica Protegida - IGP), derivados de leite bovino (ricota, leite in natura e vários tipos de queijos), derivados de mel (mel de várias plantas/flores, multiflores, pólen, geleia real, própolis, hidromel, cera e vários cosméticos fabricados a partir do mel).

É possível observar a grande diversidade agroalimentar e inovações produtivas que as agroindústrias italianas conseguem produzir e colocar nos mercados, nas diferentes cadeias produtivas das iniciativas, indo bem além do que os casos brasileiros apresentam.

\section{OS MERCADOS E CANAIS DE COMERCIALIZAÇÃO DOS ALIMENTOS}

Esta seção discute os mercados e canais de comercialização construídos pelas iniciativas brasileiras e italianas, comparativamente, utilizando-se de uma classificação dos canais de comercialização, de forma a melhor representar e agrupar a realidade comercial em torno das agroindústrias.

Os fluxos comerciais das agroindústrias brasileiras formam seis conjuntos (Quadro 6): (a) compras públicas (Programa de Aquisição de Alimentos da Agricultura Familiar - PAA e Programa Nacional de Alimentação Escolar - PNAE); (b) cadeias curtas ou vendas diretas agricultor-consumidores (vendas nas ruas, trabalho, casas, propriedades rurais, na agroindústria); (c) vendas em eventos (feiras da agricultura familiar, festas e expofeiras); (d) cadeias longas de abastecimento e distribuição (vendas a supermercados, intermediários e atacadistas distantes); (e) pontos formais de vendas (supermercados, bares, "bodegões", restaurantes, cantinas); (f) os novos canais de comercialização das organizações sociais coletivas e em redes (cooperativas, quiosques, associações de agricultores).

Salienta-se a relevância das cadeias curtas como principal forma de comercialização construída pelas agroindústrias, com $23,31 \%$ das vendas anuais (IBGE, 2006). As cadeias curtas são canais de comercialização em que as transações são feitas de forma direta entre os agricultores e consumidores. Essas vendas são caracterizadas como cadeias curtas como as definem Renting, Marsden e Banks (2003), em virtude dos alimentos percorrerem poucos quilômetros entre o local de produção, venda e consumo.

Isso ocorre especialmente em função do tipo de produto/alimento vendido, da grande frequência das transações entre agricultores e consumidores, existência de fidelidade e confiança dos consumidores nos produtos e alimentos e, principalmente, devido à situação institucional das agroindústrias (alto grau de informalidade) (WILKINSON, 2008). A informalidade institucional das agroindústrias parece ser o grande problema que esse tipo de circuito de vendas possui para viabilizar-se, por exemplo, pesquisas no RS indicam que $72,64 \%$ das iniciativas são informais perante os requisitos sanitários estabelecidos pelas agências de regulação do Estado (PELLEGRINI; GAZOLLA, 2008).

O Quadro 7 apresenta os principais canais de comercialização e mercados construídos pelas agroindústrias italianas. No caso das experiências italianas uma tipologia dos canais de comercialização aponta para a seguinte importância: (a) as cadeias curtas agroalimentares (vendas na propriedade rural, em feiras, 'Km zero', com as atividades de agro turismo, entrega direta aos consumidores, sites das propriedades); (b) cadeias longas de abastecimento (algumas experiências exportam seus produtos e alimentos para outros países, inclusive EUA e Canadá); (c) vendas em eventos (festas típicas locais, feiras internacionais, nacionais e locais/regionais); (d) comércio em negócios (são as vendas em supermercados, restaurantes, lojas especializadas de alimentos, negócios de gastronomia); (e) canais coletivos e associativos (Grupo de Aquisições Solidárias - GAS, mercados dos agricultores - farmers markets, associações de agricultores com ponto de venda). 
QUADRO 6 - Brasil (RS): Os mercados e canais de comercialização construídos pelas agroindústrias

\begin{tabular}{|c|l|}
\hline Agroindústrias & \multicolumn{1}{c|}{ Tipos de canais de comercialização } \\
\hline Agroindústria Prevedello & Vendas na própria agroindústria, nos supermercados locais, bares e "bodegas”, Cooperçara. \\
\hline Cooperativa Biorga & $\begin{array}{l}\text { Cadeias longas (supermercados de SP e RJ), quiosques da Recosol (Erval Seco e Frederico Westphalen), } \\
\text { Supermercados locais, vendas na própria agroindústria, expo feiras municipais locais e de SC, Feira do } \\
\text { Produtor de Palmitos - SC, mercados institucionais (PAA), Corac (PAA) e PAA formação de estoques } \\
\text { (CONAB), Cooperativa Coolmeia, Cooperbiorga. }\end{array}$ \\
\hline Strack Alimentos Naturais & $\begin{array}{l}\text { Cadeias longas e atacadistas (Porto Alegre, SC, RJ, PR, MG), intermediários, Cooperativa Colônia, } \\
\text { supermercados locais, vendas na própria agroindústria, expo feiras locais, mercados institucionais } \\
\text { (PNAE) 2 municípios, quiosques da Recosol, Cooperçara. }\end{array}$ \\
\hline Agroindústria Gehen & $\begin{array}{l}\text { Vendas na própria agroindústria, Associação dos Trabalhadores de Seberi (ATS), Corac, "bodegas" } \\
\text { locais, Ervateira Alto Uruguai, expo feira municipal }\end{array}$ \\
\hline Agroindústria Ludke & $\begin{array}{l}\text { Feiras da agricultura familiar (Porto Alegre, DF, RJ e regionais), vendas na própria agroindústria, } \\
\text { quiosques da Recosol, supermercados municipais, nas casas e locais de trabalho dos consumidores, } \\
\text { restaurantes e cantinas, expo feiras locais, mercados institucionais (PAA), Cooperac. }\end{array}$ \\
\hline Agroindústria Jotti & $\begin{array}{l}\text { Feiras da agricultura familiar (RS, RJ, DF e regionais), 1 supermercado em Porto Alegre, e } \\
\text { supermercados locais e regionais (10 a 12 municípios), vendas nas ruas, casas e locais de trabalho, } \\
\text { vendas na própria agroindústria, Cooperac. }\end{array}$ \\
\hline $\begin{array}{c}\text { Agroindústria Zonta } \\
\text { (antiga Natufred) }\end{array}$ & $\begin{array}{l}\text { Mercados institucionais 7 municípios e escolas (PAA e PNAE), supermercados locais, Coopraf, } \\
\text { quiosques da Recosol, vendas na própria agroindústria, expo feiras locais e do RS, feiras da agricultura } \\
\text { familiar (RS, RJ, DF), vendas nas casas e locais de trabalho, STR, Feira do Produtor de Frederico } \\
\text { Westphalen }\end{array}$ \\
\hline
\end{tabular}

Fonte: Pesquisa de campo (2011)

Dos mercados construídos pelas iniciativas italianas também chamam atenção as cadeias curtas agroalimentares, que são proeminentes em quase todas as sete experiências investigadas. Se no Brasil esses canais diretos são assim constituídos principalmente em função da informalidade das experiências, na Itália, as crises alimentares (por exemplo, a 'vaca louca'), consumidores reflexivos e os princípios em torno da saudabilidade da alimentação e sustentabilidade ambiental que fazem com que estes circuitos diretos de comercialização operem de forma mais abrangente. Segundo Renting, Marsden e Banks (2003) em torno de $20 \%$ da produção da Europa circulam por esses mercados locais.

Há outras peculiaridades mercadológicas interessantes de serem mencionadas. A primeira é a relevância das cadeias longas de abastecimento com as vendas para outros países, impulsionada pelos acordos em torno da formação da União Europeia e pela própria Política Agrícola Comum (PAC). Tanto no Brasil, como na Itália, esse aspecto é transversal às agroindústrias, colocando ênfase na formulação de Sonnino e Marsden (2006), de que as redes agroalimentares alternativas conectam-se e integram-se com as convencionais. Outra particularidade na construção dos mercados italianos é o comércio eletrônico (via site das propriedades), uma estratégia muito utilizada na Itália e que no Brasil é quase inexistente. Também chama a atenção os processos organizativos dos consumidores reflexivos, que passam a demandar uma nova dinâmica dentro do sistema agroalimentar, mediante ação social ativa (agência) e coletiva, por meio da formação dos GAS, que estimulam a discussão crítica, alimentação saudável e sustentável (LONG, 2001; BRUNORI; ROSSI; GUIDI, 2012).

\section{POLÍTICAS PÚBLICAS E O AMBIENTE INSTITUCIONAL}

Esta seção objetiva discutir alguns indicadores, comparativamente entre as duas regiões investigadas, em torno das políticas públicas que apoiam as agroindústrias, legislações agroalimentares e a situação institucional das iniciativas perante os diferentes níveis regulatórios da produção, distribuição e consumo dos alimentos pelo Estado. 
QUADRO 7 - Itália (Toscana): Os mercados e canais de comercialização construídos pelas agroindústrias

\begin{tabular}{|c|c|}
\hline Agroindústrias & Tipos de canais de comercialização \\
\hline Azienda Lischeto & $\begin{array}{l}\text { Vendas na propriedade rural (com e sem agro turismo); organização de eventos e festas na } \\
\text { propriedade; venda a eventos e festas; cestas para casamentos e presentes; venda a negócios formais } \\
\text { (ex.: supermercados); Associação Empório Del Gusto (constituída de } 33 \text { agricultores para venda } \\
\text { em cadeias curtas); site da propriedade; exportação para outros países (França, EUA e Taiwan); } \\
\text { feiras internacionais (ex.: Biofach - Alemanha); }\end{array}$ \\
\hline Azienda Floriddia & $\begin{array}{l}\text { Grupo de Aquisições Solidárias (GAS); farmers markets; restaurantes e pizzarias; pontos formais } \\
\text { de vendas de alimentos, negócios e gastronomia; site da propriedade; vendas em toda a Itália } \\
\text { pelo e-commerce; vendas na propriedade rural (com e sem agro turismo); vendas em Km zero } \\
\text { (municípios e locais regionais); }\end{array}$ \\
\hline Cooperativa Orto \& Co Frutta & $\begin{array}{l}\text { Vendas a redes de supermercados (Carrefour, Coop e Conad); negócios de gastronomia (lojas } \\
\text { especializadas); festas típicas de agricultores; feiras; GAS; }\end{array}$ \\
\hline $\begin{array}{l}\text { Caseificio Pedrazzi } \\
\quad \text { Giampaolo }\end{array}$ & $\begin{array}{l}\text { Sorveteria local; vendas na propriedade; organização de almoços/jantas na propriedade para grupos } \\
\text { de pessoas; GAS locais e regionais; negócios e restaurantes locais; festas típicas locais (ex.: festa } \\
\text { do tartufo); feiras locais e regionais; e-comerce; }\end{array}$ \\
\hline Azienda Fonte di Foiano & $\begin{array}{l}\text { Venda para exportação a } 12 \text { países (Canadá compra em torno de } 40 \% \text { da produção); vendas a } \\
\text { dois supermercados (Coop e Esselunga); vários pontos de vendas na Itália; visitas na propriedade } \\
\text { com degustações; vendas junto com a atividade de agro turismo; vendas diretas a consumidores; }\end{array}$ \\
\hline Azienda La Stalletta & $\begin{array}{l}\text { Venda a domicílio (entrega nas casas), confecção de cestas dos produtos para presentes, vendas } \\
\text { durante as visitas guiadas a agroindústria, venda direta na propriedade rural e agroindústria, } \\
\text { Mercados da 'Campanha amiga' (vendas locais organizadas pelo Sindicato COLDIRETI), vendas } \\
\text { em outros municípios locais, mas de forma direta aos consumidores, vendas em mercados doas } \\
\text { agricultores em Volterra e Livorno, feiras organizadas pelo Slow Food, vendas em pequenos } \\
\text { negócios alimentares e supermercados; }\end{array}$ \\
\hline Azienda Dr. Pescia & $\begin{array}{l}\text { Exportações para a América do Norte, China e Alemanha; visitas guiadas com degustação e } \\
\text { venda dos produtos junto com agro turismo; vendas no site da propriedade, vendas diretas aos } \\
\text { consumidores, venda a supermercados (COOP), a negócios especializados de gastronomia, vendas } \\
\text { em eventos do Slow Food (Salão do Gosto - Torino); }\end{array}$ \\
\hline
\end{tabular}

Fonte: Pesquisa de campo (2011) e Sites das propriedades rurais: http://www.agrilischeto.com/ (2015); http://www.ilmulinoapietra. it/ (2015); http://www.fontedifoiano.it/ (2015); http://www.lastalletta.it/ (2016); http://www.dottorpescia.com/ (2016)

O Quadro 8 apresenta as principais ações do Estado para fortalecimento das agroindústrias, tanto no Brasil como na Itália. Nos casos brasileiros, as políticas existentes ajudaram a criar várias agroindústrias (no caso do RS, estudos apontam que $9,43 \%$ destas indústrias originamse em função do apoio governamental) (PELLEGRINI; GAZOLLA, 2008), especialmente fornecendo crédito rural para a montagem da infraestrutura de produção (instalações, máquinas e equipamentos). São exemplos disso o Pronaf Agroindústria e o Programa Territórios Rurais/da Cidadania.

As políticas públicas para agroindustrialização estão mais centradas no Governo Federal, embora, alguns estados (Fábrica do Agricultor no PR, Programa de Agroindústria Familiar - PAF no RS, Desenvolver em $\mathrm{SC})$ e, em menor medida, alguns municípios possuem ações específicas (RAUPP, 2009). Estes programas agem de forma fragmentada e não integrada a outros programas e ações governamentais. Por exemplo, no caso da alimentação, é notória a ligação do tema com os aspectos de saúde, ambientais e de segurança alimentar, contudo, essa integração não é realizada pelas políticas públicas no Brasil.

Em relação à construção social dos mercados das experiências, destacam-se as ações da EMATER/ RS e do PAF/RS na organização de feiras municipais, feiras de agricultores e outros espaços como a EXPOINTER (Feira Internacional de Esteio/RS) para venda dos alimentos e produtos. Além disso, programas institucionais como o Programa de Aquisição de Alimentos da Agricultura Familiar (PAA) e o Programa Nacional de Alimentação Escolar (PNAE) que não foram desenhados com essa finalidade, mas que tem dado escoamento à boa parte da produção colocada nos 
mercados das agroindústrias. Os produtos colocados nos mercados são, em geral, industrializados de diversas cadeias produtivas e com poucas distinções qualitativas. As políticas públicas brasileiras também possuem pouca ênfase em aspectos inovativos e de gestão ambiental das agroindústrias.

Já no caso italiano, as políticas públicas pouco auxiliaram no nascimento das experiências (em um caso somente, conforme o Quadro 3), e foi a ação social proativa dos agricultores que as originaram (LONG, 2001). Por outro lado, as políticas públicas prestam apoios mais efetivos ao desenvolvimento das experiências, desde recursos vindos pela PAC a fundo perdido, como do Ministério da Política Agrícola, Alimentar e Florestal (MIIPAF), Região Toscana e a rubrica 123, que é específica dentro do Plano Regional de Desenvolvimento Rural (PDR) para apoiar a agregação de valor aos alimentos. Nota-se que essas políticas agem em vários níveis, inclusive, no âmbito macro da União Europeia (UE). As ações são mais integradas entre os níveis territoriais das políticas (Politica Agrícola Comum da UE - PAC, nacional e regional) e, em relação aos aspectos ambientais, de saúde, territoriais e de segurança alimentar, comparativamente, ao Brasil (Quadro 8).

QUADRO 8 - Brasil (RS) e Itália (Toscana): Descrição de alguns indicadores em torno das políticas públicas que apoiam as agroindústrias

\begin{tabular}{|c|c|c|}
\hline Parâmetros & Brasil (RS) & Itália (Toscana) \\
\hline $\begin{array}{l}\text { Apoio no surgimento das } \\
\text { agroindústrias }\end{array}$ & $\begin{array}{l}\text { Muito importante na origem de muitas } \\
\text { experiências }\end{array}$ & Importante no surgimento de algumas iniciativas \\
\hline $\begin{array}{l}\text { Modo de atuação das políticas } \\
\text { públicas }\end{array}$ & Fragmentada e por programas & $\begin{array}{l}\text { Mais integrada entre a PAC, MIPAAF e através } \\
\text { do Programa de Desenvolvimento Rural } \\
\text { Toscano (PDR) }\end{array}$ \\
\hline $\begin{array}{l}\text { Níveis de atuação das políticas } \\
\text { públicas }\end{array}$ & $\begin{array}{l}\text { Vários níveis governamentais (município, } \\
\text { estado e federal) }\end{array}$ & Regional, nacional e em nível de EU \\
\hline $\begin{array}{l}\text { Tipos de apoios prestados a } \\
\text { produção e processamento de } \\
\text { alimentos }\end{array}$ & $\begin{array}{l}\text { MDA (Programa de Agroindustrialização } \\
\text { Familiar); Crédito rural (PRONAF e PAF/ } \\
\text { RS); Programas territoriais (infraestrutura de } \\
\text { processamento e comercialização); EMATER } \\
\text { e PAF/RS (apoio a formalizações, formação de } \\
\text { agricultores, assistência técnica); Programas e } \\
\text { apoios municipais (recursos, crédito rotativos); }\end{array}$ & $\begin{array}{l}\text { Recursos a fundo perdido da PAC (modernização } \\
\text { das propriedades, recursos para a produção } \\
\text { biológica, assentamento de jovens); MIPAAF } \\
\text { (apoio as cadeias produtivas e as empresas } \\
\text { rurais); Toscana: PDR e Plano Regional } \\
\text { Agrícola-Florestal 2012-15 (apoio a frutas } \\
\text { e óleo de oliva transformados); recursos } \\
\text { provinciais e da ARSIA (Agência Regional } \\
\text { de Inovação); Rubrica } 123 \text { (apoio a agregação } \\
\text { de valor) }\end{array}$ \\
\hline $\begin{array}{l}\text { Apoio na construção de canais de } \\
\text { comercialização e dos mercados }\end{array}$ & $\begin{array}{l}\text { Apoio na construção dos mercados (PAA } \\
\text { e PNAE); financiamentos de embalagens e } \\
\text { participações em feiras e eventos (PAF/RS) }\end{array}$ & $\begin{array}{l}\text { MIPAAF: apoio por cadeias produtivas; } \\
\text { Toscana (vários tipos de estímulos às cadeias } \\
\text { curtas. Ex.: farmers markets) }\end{array}$ \\
\hline $\begin{array}{l}\text { Tipo de produto privilegiado pelo } \\
\text { apoio das políticas públicas }\end{array}$ & $\begin{array}{l}\text { Agroindustrializados em geral, com exceção } \\
\text { dos adquiridos pelos PAA e PNAE, em que } \\
\text { aparecem os orgânicos e/ou agroecológicos }\end{array}$ & $\begin{array}{l}\text { Biológicos; produtos típicos locais; com } \\
\text { Indicação Geográfica (IG) e Denominação de } \\
\text { Origem (DO) }\end{array}$ \\
\hline Políticas de inovação & $\begin{array}{l}\text { Inexistente no Brasil. No RS os APLs de } \\
\text { agroindústria poderiam ser considerados }\end{array}$ & $\begin{array}{l}\text { Muito presente, inclusive com agências } \\
\text { específicas para este fim (ARSIA na Toscana) } \\
\text { e ações no PDR }\end{array}$ \\
\hline Políticas territoriais & $\begin{array}{l}\text { Pouco efetivas em apoiar as agroindústrias; } \\
\text { fornecem infra estruturas produtivas e } \\
\text { comerciais }\end{array}$ & $\begin{array}{l}\text { Pagamentos diretos as famílias para gestão } \\
\text { da paisagem, indiretamente apoiando as } \\
\text { agroindústrias }\end{array}$ \\
\hline Políticas de gestão ambiental & $\begin{array}{l}\text { Fragmentadas e pouco efetivas; agem aplicando } \\
\text { sanções as agroindústrias }\end{array}$ & $\begin{array}{l}\text { Estimulam a gestão dos recursos ambientais; } \\
\text { existência de planos ambientais regionais }\end{array}$ \\
\hline
\end{tabular}

Fonte: Pesquisa de campo (2011); Site: https://www.politicheagricole.it/ (2015); Site: http://www.regione.toscana.it/ (2015) 
Em relação ao apoio prestado pelo Estado na construção dos mercados, pode-se dizer que este é bem mais efetivo do que no Brasil. Há ações do MIIPAF e da Região Toscana, quase todas com ênfase na construção de cadeias curtas alimentares ${ }^{9}$. Importante mencionar que essas diversas ações governamentais não apoiam uma produção indiferenciada das agroindústrias, já que elas possuem como princípios a produção biológica, produtos típicos locais, alimentos com IG ou DO, assentamento de jovens e levando em conta as cadeias produtivas estratégicas ao desenvolvimento rural (por exemplo, na Toscana a de frutas e de óleo de oliva). As políticas de inovação, gestão territorial e ambiental também são mais efetivas em relação às brasileiras, possuindo, inclusive, previsão de recursos e ações específicas dentro dos PDR's

${ }^{9}$ Por exemplo, na Região da Toscana, podem-se enumerar as seguintes ações governamentais de fomento a construção de mercados: a) Mercados dos produtores: mercados em praças, centro de cidades, ruas, locais de circulação das pessoas; b) Presentes da Toscana: feiras em dias que antecedem datas festivas. Ex.: Natal; c) Espaços locais de venda direta: pontos de vendas fixos nas cidades dos próprios agricultores; funcionam como negócios; d) Pactos de cadeias curtas: acordos de venda com restaurantes, serviços de alimentação e comércio; e) Mesa mais saudável: inicio de inserção dos alimentos em escolas públicas; f) Outras atividades: agricultura em praça; apoio a construção de sites; ações de animação e materiais publicitários; etiquetas e preços; eventos de artes, cultura e comida; logo da fileira corta Toscana, sagas típicas e específicas (festas de alimentos e produtos) (REGIONE TOSCANA, 2013). e agências responsáveis a nível regional, como é o caso da Agência Regional de Desenvolvimento e Inovação no Setor Agrícola (ARSIA).

O Quadro 9 mostra as diferenças em torno das legislações agroalimentares dos dois países. De maneira geral, no contexto italiano, as legislações alimentares são mais abertas a apelos sociais, ecológicos, artesanais, éticos e aos processos naturais de produção. São exemplos disso, a possibilidade de uso da madeira nas instalações das agroindústrias e o uso do leite cru na fabricação dos queijos, dois aspectos que no Brasil são proibidos. Também há diferenças nos controles de qualidade agroalimentar. Enquanto na Itália este é realizado na produção das matérias primas e ao longo de todo o processo de fabricação dos produtos, no Brasil, esses mesmos controles são feitos principalmente por exames laboratoriais nos produtos finais (químicos, físicos, microbiológicos).

A legislação italiana também é mais abrangente em considerar fatores ligados ao bem estar dos animais, sistemas de controle da conformidade das IG e DO, além de proibir o ingresso dos OGM's. Em função de todo esse arcabouço legislativo brasileiro mais complexo em normativas e regramentos voltados aos processadores de alimentos e às agroindústrias é que

QUADRO 9-Brasil (RS) e Itália (Toscana): Descrição de alguns indicadores em torno das legislações agroalimentares e do ambiente institucional em que estão inseridas as agroindústrias

\begin{tabular}{|l|l|l|}
\hline \multicolumn{1}{|c|}{ Parâmetros } & \multicolumn{1}{|c|}{ Brasil (RS) } & \multicolumn{1}{|c|}{ Itália (Toscana) } \\
\hline Níveis das legislações agroalimentares & Federal, Estadual e Municipal & EU, Nacional e Regional \\
\hline $\begin{array}{l}\text { Grau de exigência das legislações } \\
\text { agroalimentares }\end{array}$ & $\begin{array}{l}\text { Maior, especialmente as federais e } \\
\text { estaduais }\end{array}$ & $\begin{array}{l}\text { Menor, permitindo várias práticas que são } \\
\text { proibidas no Brasil }\end{array}$ \\
\hline $\begin{array}{l}\text { Local de incidência dos controles de } \\
\text { qualidade na cadeia produtiva alimentar }\end{array}$ & $\begin{array}{l}\text { Alimentos já processados; controles de } \\
\text { qualidade pós processamento }\end{array}$ & $\begin{array}{l}\text { Controle de qualidade na matéria prima; } \\
\text { alimentos já processados }\end{array}$ \\
\hline Informalidade institucional & Muito grande nas experiências & Quase inexistente \\
\hline $\begin{array}{l}\text { Possibilidade de fabricar alimentos } \\
\text { artesanais }\end{array}$ & $\begin{array}{l}\text { Menor, devido à uniformidade dos } \\
\text { processos produtivos }\end{array}$ & $\begin{array}{l}\text { Maior, devido à diferenciação de processos } \\
\text { de elaboração }\end{array}$ \\
\hline Grau de inovação presente nos alimentos & $\begin{array}{l}\text { Menor, devido a pouca criatividade e } \\
\text { história agrária acumulada dos atores }\end{array}$ & $\begin{array}{l}\text { Maior, devido a grande criatividade dos } \\
\text { atores e sua longa história agrária }\end{array}$ \\
\hline $\begin{array}{l}\text { Abertura da legislação a apelos sociais, } \\
\text { ecológicos e éticos }\end{array}$ & Quase inexistente & Muito presente \\
\hline Aspectos ligados ao bem estar animal & Pouco considerados e presentes & Muito importantes e presentes \\
\hline $\begin{array}{l}\text { Existência de IG e DO nos alimentos e } \\
\text { produtos }\end{array}$ & $\begin{array}{l}\text { Incipiente; no RS apenas para alguns } \\
\text { produtos (vinhos) }\end{array}$ & $\begin{array}{l}\text { Muito desenvolvidas; MIPAAF-sistemas } \\
\text { para vinhos e demais alimentos e produtos }\end{array}$ \\
\hline $\begin{array}{l}\text { Organismos Geneticamente Modificados } \\
\text { (OGMs) }\end{array}$ & Alimentos permitidos nacionalmente & $\begin{array}{l}\text { Alimentos proibidos na Toscana e } \\
\text { nacionalmente }\end{array}$ \\
\hline
\end{tabular}

Fonte: Pesquisa de campo (2011); Site: https://www.politicheagricole.it/ (2015); Site: http://www.regione.toscana.it/ (2015) 
o país possui um grau de inovação menor, alimentos com pouca artesanalidade e diferenciação de suas qualidades, mas, principalmente, um alto índice de agroindústrias na completa informalidade institucional nos mercados (Quadros 9 e 10). Estudos já conduzidos no RS evidenciaram que mais de $70 \%$ destas estão nessa situação perante os aspectos sanitários exigidos pelo Estado (72,64\%) (PELLEGRINI; GAZOLLA, 2008).

No Quadro 10, verifica-se que o ambiente institucional italiano também é passível de controles por diversos órgãos e agências reguladores da produção, distribuição e consumo de alimentos, em vários níveis territoriais nacionais, bem como, para todo o bloco europeu. Entretanto, todas as sete iniciativas de agroindústrias investigadas conseguiram adequar-se ao ambiente normativo italiano em nível regional, nacional e, há inclusive, experiências que conseguem acessar os mercados alimentares para fora do bloco europeu (Quadro 9), evidenciando que a formalização institucional das agroindústrias é uma possibilidade mais real ao contexto italiano do que no brasileiro.

QUADRO 10 - Brasil (RS) e Itália (Toscana): Situação institucional das agroindústrias quanto às legislações agroalimentares

\begin{tabular}{|c|c|c|c|}
\hline $\begin{array}{l}\text { Agroindústrias } \\
\text { (Brasil - RS) }\end{array}$ & $\begin{array}{l}\text { Ambiente institucional } \\
\text { (legisl. agroalimentares) }\end{array}$ & $\begin{array}{l}\text { Agroindústrias } \\
\text { (Itália - Toscana) }\end{array}$ & $\begin{array}{l}\text { Ambiente institucional } \\
\text { (legisl. agroalimentares) }\end{array}$ \\
\hline $\begin{array}{l}\text { Agroindústria } \\
\text { Prevedello }\end{array}$ & Informal & Azienda Lischeto & $\begin{array}{l}\text { Formal: ASL (Agência Sanitária da Toscana); } \\
\text { CCPB (Certificação Biológica); MIPAAF } \\
\text { (ICQRF - Inspetoria Central de Controle da } \\
\text { Qualidade e Repressão Anti fraude dos Produtos } \\
\text { Agroalimentares); MIPAAF (NAC - Núcleo } \\
\text { Policial Anti fraude); Livro Branco da EU; }\end{array}$ \\
\hline Cooperativa Biorga & $\begin{array}{l}\text { Formal: Certificação Ecovida } \\
\text { (Agroecológica), CNPJ, } \\
\text { Secretaria Regional da Saúde } \\
\text { (MS) e FEPAM }\end{array}$ & Azienda Floriddia & $\begin{array}{l}\text { Formal: MIPAAF (ICQRF); Certificação } \\
\text { orgânica (Organismo Biológico Europeu, } \\
\text { Coordenamento Toscano de Produtores } \\
\text { Biológicos, Rede Semi Rural, Solo e Saúde, } \\
\text { Água Vitalizada Grander); }\end{array}$ \\
\hline $\begin{array}{l}\text { Strack Alimentos } \\
\text { Naturais }\end{array}$ & $\begin{array}{l}\text { Formal: CNPJ, FEPAM, } \\
\text { Secretaria Regional da Saúde } \\
\text { (MS) }\end{array}$ & $\begin{array}{l}\text { Cooperativa Orto \& } \\
\text { Co Frutta }\end{array}$ & Formal: ASL; MIPAAF (ICQRF); \\
\hline $\begin{array}{l}\text { Agroindústria } \\
\text { Gehen }\end{array}$ & $\begin{array}{l}\text { Informal: apenas com Alvará de } \\
\text { Licença de Municipal }\end{array}$ & $\begin{array}{l}\text { Caseificio Pedrazzi } \\
\text { Giampaolo }\end{array}$ & $\begin{array}{l}\text { Formal: ASL; MIPAAF (ICQRF); Certificação } \\
\text { orgânica; Legislação ambiental sobre áreas de } \\
\text { conservação (parques); }\end{array}$ \\
\hline $\begin{array}{l}\text { Agroindústria } \\
\text { Ludke }\end{array}$ & $\begin{array}{l}\text { Formal: Sistema de Inspeção } \\
\text { Municipal (SIM) }\end{array}$ & $\begin{array}{l}\text { Azienda Fonte di } \\
\text { Foiano }\end{array}$ & $\begin{array}{l}\text { Formal: ASL; Consorcio de Óleos Toscanos } \\
\text { (IGP), Instituto de Ácidos Graxos; MIPAAF } \\
\text { (ICQRF); MIPAAF (NAC); ARPA (Agência } \\
\text { Regional de Proteção do Ambiente); MIPAAF } \\
\text { (Corpo Florestal do Estado); }\end{array}$ \\
\hline Agroindústria Jotti & $\begin{array}{l}\text { Formal: Sistema de Inspeção } \\
\text { Municipal (SIM) }\end{array}$ & Azienda La Stalletta & $\begin{array}{l}\text { Formal: ASL; MIPAAF (ICQRF); Associação } \\
\text { de Criadores de Animais (controles veterinários } \\
\text { do rebanho); }\end{array}$ \\
\hline $\begin{array}{l}\text { Agroindústria Zonta } \\
\text { (antiga Natufred) }\end{array}$ & $\begin{array}{l}\text { Formal: Registro no MAPA, } \\
\text { Alvará de Licença Municipal, } \\
\text { CNPJ, Licença Ambiental } \\
\text { (sendo encaminhado) e Bloco de } \\
\text { Produtor ("Sabor Gaúcho") }\end{array}$ & Azienda Dr. Pescia & $\begin{array}{l}\text { Formal: ASL; MIPAAF (ICQRF); MIPAAF } \\
\text { (NAC); }\end{array}$ \\
\hline
\end{tabular}

Fonte: Pesquisa de campo (2011); Site: https://www.politicheagricole.it/ (2015); Site: http://www.regione.toscana.it/ (2015) 


\section{CONSIDERAÇÕES FINAIS}

O objetivo do trabalho foi o de comparar as estratégias de reprodução socioeconômicas das agroindústrias familiares no Brasil e na Itália, contribuindo com o avanço dos conhecimentos na área, que carece de estudos comparativos internacionais.

Ao pontuar algumas conclusões da pesquisa, podese dizer que, em relação aos casos estudados, os brasileiros diferem dos italianos em relação a sua origem devido à situação de crise na agricultura 'moderna' (o squeeze) e o apoio dado pelo Estado com políticas públicas ao setor. Já os italianos surgem mais ligados ao potencial de agregação de valor a produção in natura e a potencialidades que os novos mercados oferecem (demanda de alimentos com qualidades específicas e pela ação social ativa dos consumidores reflexivos e críticos).

Em relação aos tipos de produtos elaborados entre os dois países as diferenças são marcantes. Enquanto no Brasil os produtos agroindustrializados em pequena escala são menos diversificados e fabricados de uma forma muito idêntica entre experiências (possuem pouco grau de inovação e diferenciação em seus atributos qualitativos). Os alimentos e produtos italianos são sensíveis aos apelos sociais, ecológicos, bem-estar animal, orgânicos, alimentos típicos locais, IG e DP, entre outras estratégias de valorização e qualificação agroalimentar. Além disso, é visível a grande diversidade agroalimentar da Região Toscana, famosa mundialmente pela sua gastronomia agroalimentar ligada à pequena agricultura.

Em relação à construção dos mercados e canais de comercialização das agroindústrias, um fio condutor que liga igualmente os dois países, é a protuberância dos circuitos curtos alimentares como estratégia principal de comercialização. Nos dois casos, nesses mercados, circulam em torno de $20 \%$ da produção que é comercializada. No Brasil, a grande inovação institucional são os mercados criados pelo PAA e PNAE. Já os casos italianos evidenciam inovações mercantis interessantes que podem ser 'apropriadas' pelos atores sociais e políticas públicas de comercialização para a agricultura familiar no Brasil, por exemplo, a constituição dos GAS, as vendas eletrônicas em sites das próprias propriedades, a abertura de lojas e negócios especializados em alimentos pelos próprios agricultores e os mercados biológicos (farmers markets).

Em relação às políticas públicas e ao ambiente institucional em que as agroindústrias operam, vale destacar duas coisas. Primeiro, as políticas públicas brasileiras estão focadas no fornecimento de crédito rural para consolidação de infraestruturas produtivas das experiências, devido às legislações alimentares exigirem isso dos agricultores. Já na Itália, as ações do Estado visam a promover de forma mais integrada à alimentação saudável, sustentabilidade ambiental, artesanalidade e os processos produtivos mais próximos dos ritmos naturais. O segundo aspecto é que isso ocorre devido à legislação alimentar italiana ser mais aberta em possibilidades de elaboração dos alimentos de formas diversas (qualificações distintas), e vai além dos padrões higiênico-industriais estabelecidos no Brasil. Nesse sentido, há várias lições que o caso italiano poderia servir de exemplo para se propor mudanças nas legislações alimentares e no ambiente institucional a que estão expostas as agroindústrias brasileiras, visando a diminuir os altos percentuais de informalidade existentes.

\section{REFERÊNCIAS}

ARFINI, F.; BELLETTI, G.; MARESCOTTI, A. Prodotti tipici e denominazioni geografiche: strumenti di tutela e valorizzazione. Roma: Edizioni Tellus. 2010, 206p.

BRUNORI, G. et al. Looking for alternatives: the construction of the organic beef chain in Mugello, Tuscany. International Journal Agricultural Resources, Governance and Ecology. Vol. 7, N. 1/2, 2008, p. 126-146.

BRUNORI, G.; ROSSI, A.; GUIDI, F. On the new social relations around and beyond food: analysing consumers' role and action in Gruppi di Acquisto Solidale (Solidarity Purchasing Groups). Sociologia Ruralis. Vol 52, Number 1, January 2012.

CONTERATO, M. A.; GAZOLLA, M.; SCHNEIDER, S. A dinâmica agrícola do desenvolvimento da agricultura familiar no Alto Uruguai, Rio Grande do Sul: suas metamorfoses e reações locais. In: TONEAU, J. F.; SAUBORIN, E. (Org.). Agricultura familiar: interações entre políticas públicas e dinâmicas locais. Porto Alegre: Editora da UFRGS, 2007. p. 13-54. 328 p. (Estudos Rurais).

GAZOLLA, M. Agricultura familiar, segurança alimentar e políticas públicas: Uma análise a partir da produção para autoconsumo no território do Alto Uruguai/RS. Dissertação de Mestrado. Programa de PósGraduação em Desenvolvimento Rural/UFRGS. Porto Alegre - RS, 287p., 2004. 
Conhecimentos, produção de novidades e ações institucionais: cadeias curtas das agroindústrias familiares. 295f. 2012. Tese (Desenvolvimento Rural). Programa de Pós Graduação em Desenvolvimento Rural, Universidade Federal do Rio Grande do Sul. Porto Alegre. 2012.

Redefinindo as agroindústrias familiares: uma conceituação baseada em suas "condições alargadas" de reprodução social. Florianópolis. VI Congresso Internacional Sistemas Agroalimentares Localizados. 2013, 29p.

GAZOLLA, M.; SCHNEIDER, S. Conhecimentos, produção de novidades e transições sociotécnicas nas agroindústrias familiares. Organizações Rurais \& Agroindustriais. Lavras, v. 17, n. 2, p. 179-194, 2015.

GAZOLLA, M.; SCHNEIDER, S. Cadeias curtas e redes agroalimentares alternativas: negócios e mercados da agricultura familiar. Porto Alegre: Editora da UFRGS, 2017, 520p. (Série Estudos Rurais).

GIDDENS, A.; ULRICH, B.; SCOTT, L. (Orgs.). Modernização reflexiva: política, tradição e estética na ordem social moderna. Tradução de Magda Lopes. São Paulo: UNESP. 1997. pp. 11-72.

GOSAMO, E. Biologico a Km zero: filiera corta, contesti solidali locali, território e ambiente. Venezia: Instituto Consumatori e Utenti. 2012, 184p.

INSTITUTO BRASILEIRO DE GEOGRAFIA E ESTATÍSTICA (IBGE). Censo Agropecuário. Brasília, 2006. v. 1. 1 CD-ROAM.

INEA. INSTITUTO NAZIONALE DI ECONOMIA AGRARIA. L'agricoltura in Toscana: caractteristiche strutturali e risultati aziendali. Report 2013. 58p.

ISTAT. ISTITUTO NAZIONALE DI STATISTICA. Italia in cifre. Rome. 2010, 36p.

LANG, T.; HEASMAN, M. Food wars: the global battle for mouths, minds and markets. London: Earthscan. 2009.

LONG, N. Development sociology: actor perspectives. Amsterdam: Routledge, 2001. 285p.
MALUF, R. S. Mercados agroalimentares e a agricultura familiar no Brasil: agregação de valor, cadeias integradas e circuitos regionais. Ensaios FEE. Porto Alegre, v. 25, n. 1 , p. 299-322, abr. 2004.

MIOR, L. C. Agricultores familiares, agroindústrias e redes de desenvolvimento rural. Chapecó: Editora Argos, 338 p., 2005.

PATRIMÔNIO DE TODOS. Disponível em < www. patrimoniodetodos.gov.br $>$. Acesso em: mai. 2016.

PELEGRINI, G; GAZOLLA, M. Caracterização e análise das agroindústrias familiares da Região do Médio Alto Uruguai (CAAF). Frederico Westphalen: [s.n.], 2006. 10 p. Projeto de pesquisa. Edital FAPERGS 001/2005-PROCOREDES.

PELlEGRINI, G.; GAZOLLA, M. A agroindústria familiar no Rio Grande do Sul: limites e potencialidades a sua reprodução social. Frederico Westphalen: URI, 2008, 200p.

PLOEG, J. D. van der.; LONG, A.; BANKS, J. Rural development: the state of the art. In: PLOEG, J. D. van der.; LONG, A.; BANKS, J.(Ed.). Living Countrysides: rural development in Europe: the state of the art. Nederlands: Elservier. 2002.

PLOEG, J. D. van der. Oltre la modernizzazione: processi di sviluppo rurale in Europa. Rubbentino Editore Srl. 2006, 146p.

PLOEG, van der J. D. Camponeses e impérios alimentares: lutas por autonomia e sustentabilidade na era da globalização. Porto Alegre: UFRGS. 2008, 372p.

PREZOTTO, L. L. Qualidade ampla: referência para a pequena agroindústria rural inserida numa proposta de desenvolvimento regional descentralizado. In: LIMA, D. M. A.; WILKINSON, J. (Org.). Inovações nas tradições da agricultura familiar. Brasília: $\mathrm{CNPq} /$ Paralelo 15 , 2002. p. 285-300.

SCHNEIDER, S.; MENEZES, M.; SILVA, A. G.; BEZERRA, I. Sementes e brotos da transição: inovação, poder e desenvolvimento em áreas rurais do Brasil. Porto Alegre: Editora da UFRGS, 2014, 240p. (Série Estudos Rurais). 
SCHNEIDER, S., GAZOLLA, M. Seeds and Sprouts of Rural Development: Innovations and Nested Markets in Small Scale On-Farm Processing by Family Farmers in South Brazil. In: MILONE, P.; VENTURA, F.; YE, J. (Eds.). Constructing a New Framework for Rural Development. 1 ed. Bingley: Emerald, 2015, v.22, p. 127-156.

SONNINO, R.; MARSDEN, T. Beyond the divide: rethinking relationships between alternative and conventional food networks in Europe. Journal of Economic Geography, Cardiff, v. 6, p. 181-199, 2006.

STUIVER, M.; WISKERKE, J. S. C. The power of Experience: Farmers' Knowledge and Sustainable Innovations in Agriculture. In: PLOEG, J. D. van der; WISKERKE, J. S. C. (Ed.) Seeds of transition: essays on novelty production, niches and regimes in agriculture. Wageningen: Royal Van Gorcum, 2004. 356 p.

STUIVER, M. Regime, change and storylines: a sociological analysis of manure practices in contemporary Dutch farming. Wageningen: Wagningen University, 2008. 175 p.

RAUPP, A. K. A orientação das políticas públicas de apoio às agroindústrias da agricultura familiar: experiências do
RS em destaque. In: Congresso da Sociedade Brasileira de Economia, Sociologia e Administração Rural, 47., Porto Alegre. Anais... v.1, 2009. 20 p.

REGIONE TOSCANA. Filiere curte. Retirado de: < http://www.regione.toscana.it/agricoltura/filiere/index. html >. Acesso: dez. 2013.

REGIONE TOSCANA. Imprese e Agricoltura. Retirado de: < http://www.regione.toscana.it/ >. Acesso: fev. 2016.

RENTING, H.; MARSDEN, T.; BANKS, J. Understanding alternative food networks: exploring the role of short food supply chains in rural development. Environment and Planning, Wageningen, v. 35, p. 393-411, 2003.

WESZ JÚNIOR, V. J. Políticas públicas de agroindustrialização: uma análise do Pronaf Agroindústria. In: CONGRESSO DA SOCIEDADE DE ECONOMIA, SOCIOLOGIAE ADMINISTRAÇÃO RURAL, 47., Porto Alegre. Anais... v.1, 2009. 21 p. 1 CD-ROAM.

WILKINSON, J. Mercados, redes e valores: o novo mundo da agricultura familiar. Porto Alegre: UFRGS. 2008, 213p. (Série Estudos Rurais). 